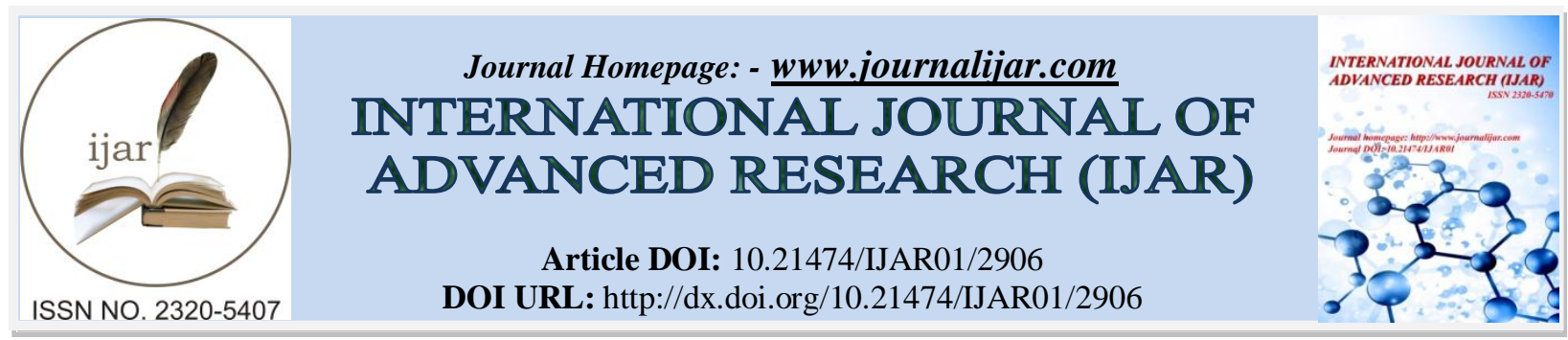

RESEARCH ARTICLE

\title{
DESIGN AND DEVELOPMENT OF A VERTICAL AXIS LOW SPEED WIND GENERATOR.
}

Mr. Rupesh Chandra Roy ${ }^{1}$ and ${ }^{*}$ Dr. Most. Hosney Ara Begum ${ }^{2}$.

1. Senior Principal Engineer, Pilot Plant and Process Development Centre, BCSIR, Dhaka.

2. Principal Scientific Officer, BCSIR Laboratories Dhaka, BCSIR, Dhaka, Bangladesh.

\section{Manuscript Info}

Manuscript History

Received: 24 November 2016

Final Accepted: 25 December 2016

Published: January 2017

Key words:-

vertical axis wind turbine, wind turbine, wind generator, low speed turbine,

fabrication technology.

\begin{abstract}
Mostly Bangladesh is a flat land with average wind speed of around 3.5 $\mathrm{m} / \mathrm{s}$. However in the coastal areas wind speed reaches up to 7-9 $\mathrm{m} / \mathrm{s}$. The potential of deploying low speed wind turbines is promising. With these view, a low speed vertical axis wind turbine together with a wind generator have been designed which can work at low speed of wind available in Bangladesh. The wind turbine and wind generator have been fabricated using locally available materials and fabrication technology. The output of the generator should be $250 \mathrm{~W}$ and usable watts should be at least $200 \mathrm{~W}$ at low cost. The generator will produce power at $450 \mathrm{rpm}$. A pulley system power drive is used to rotate the generator.
\end{abstract}

Copy Right, IJAR, 2016,. All rights reserved.

\section{Introduction:-}

The civilization is dependent on electric power. There is a relationship between GDP growth rate and electricity growth rate in a country [1]. It will therefore, be necessary to tap all sources of renewable energy and to use these in an efficient converted form for benefit of the people of Bangladesh. Primarily this will be done in remote inaccessible un-electrified area in a standalone system which is environment friendly and also save cost of grid expansion. This type of energy conversion will reduce pressure on the national power supply system. Generation of electricity through wind turbine, using available low speed of wind in Bangladesh is very much effective to provide electricity to the rural people. Because only $10 \%$ of these users have electricity connection and there are some parts of Bangladesh which will not get connected to the national grid within next 30 years [2]. Bangladesh Centre for Advance Studies (BCAS) and Local Government Engineering Department (LGED) with assistance from Overseas Development Administration (ODA) of UK launched the Wind Energy Study Project (WEST) Project in 1995 at seven places in Bangladesh [3]. These sites are Potenga, Cox's Bazar, Tecknaf, Noakhali, Charfassion, Kuakata and Kutudia. It was found that avarage anual mean wind speed in meter per second are 3.95, 3.34, 2.94, 2.96, 2.96, 4.07, 4.52 and 4.21 respectively. Later on LGED and BUET jointly studied the wind speed at 15 different places in Bangladesh. Their findings were not so satisfactory for high power wind generation. Since wind speed in Bangladesh is low, therefore low wind speed generator might be feasible. During the months starting from late October to February wind speed remains either calm or too low. This period is called lull period. The remaining seven months wind speed is quite good $[4,5]$ for this type of low speed wind generator. The peak wind speed occurs during the months of May, June and July. It will be an efficient way to generate electricity by using a newly designed wind generator for a low speed vertical axis wind turbine which can work at the available low speed of wind in Bangladesh. To meet the situation, a wind generator have been designed, fabricated and operated with capacity100W- $200 \mathrm{~W}$ at low cost.

Corresponding Author:- Dr. Most. Hosney Ara Begum

Address:- Principal Scientific Officer, BCSIR Laboratories Dhaka, BCSIR, Dhaka, Bangladesh. 


\section{Theory of wind Turbine:-}

To estimate performance of a particular wind turbine [6], one should theoretically asses the matter as bellow. For total production of energy from a turbine in one year-

AEO $=1.64 \mathrm{~d}^{2} \mathrm{~V}^{3}$

Where,

AEO =Annual energy output, KW/year,

$\mathrm{d}=$ Rotor diameter, meters and

$\mathrm{V}=$ Annual average wind speed, $\mathrm{m} / \mathrm{s}$

If it is required to reduce the cost of the turbine for an energy efficient one, it is necessary to reduce the size of peak demand electrical loads.

To design a wind generator, let us consider the elementary two pole dc machine in the figure2 (A).

The polarity of the induced emf for clockwise rotation, follow Lenz's law, figure 2(b). When angle $\theta$ (angle between magnetic axis of the stator and rotor) is zero or $\pi$, the voltage induced in the armature coil is zero. It is assumed that, for polarities of the field poles and direction of rotation, brush b1 always positive and brush b2 always negative.

A full pitch armature coil of one or more turns is one that spans a pole pitch. In a two pole machine a full pitch coil spans the diameter and in a P-pole machine it spans a chord that subtends an angle of $2 \pi / \mathrm{P}$ on the armature periphery.
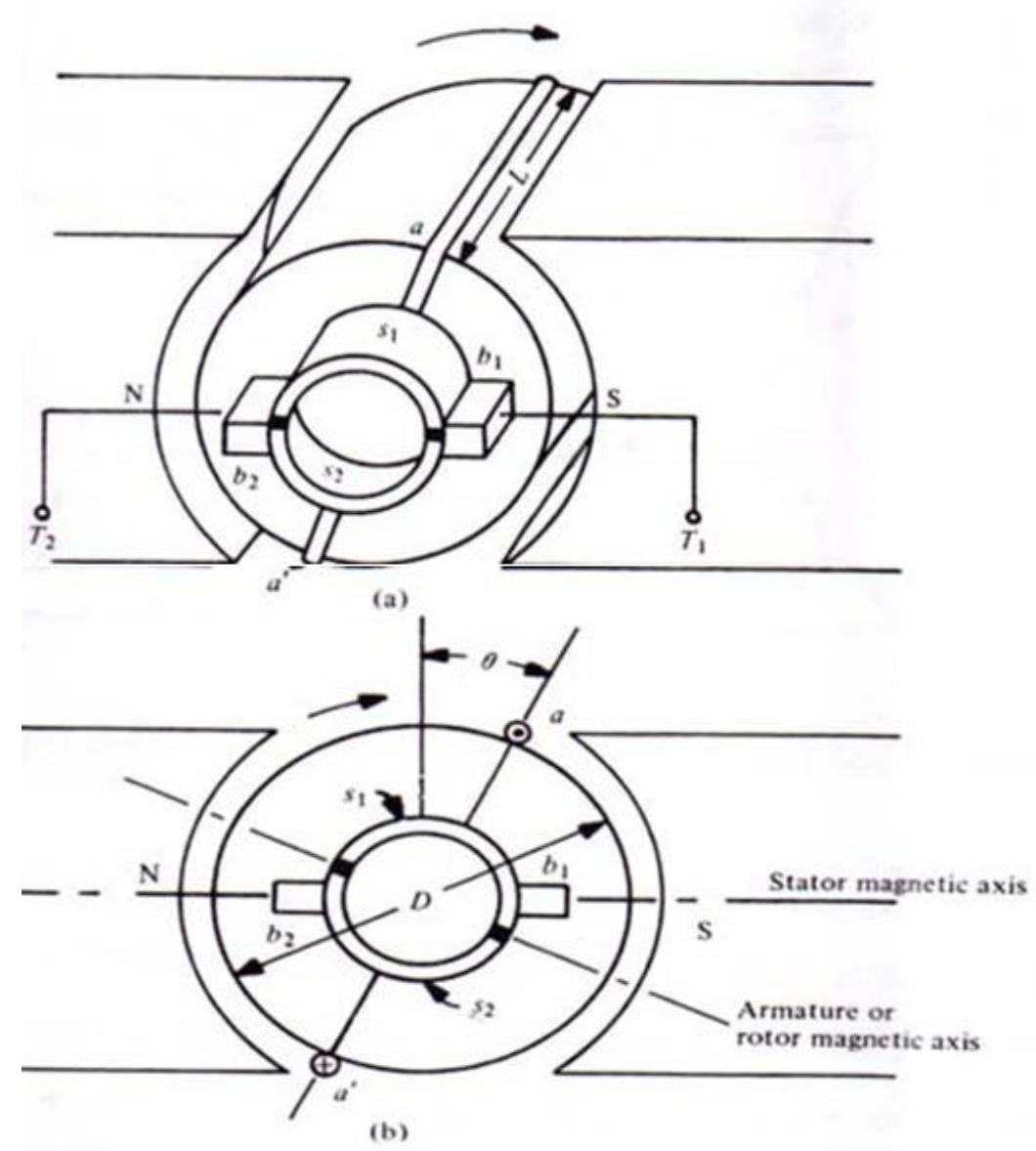

Figure 2 A:- Elementary two-pole dc machine. (a) Partial view (b) Simplified view 


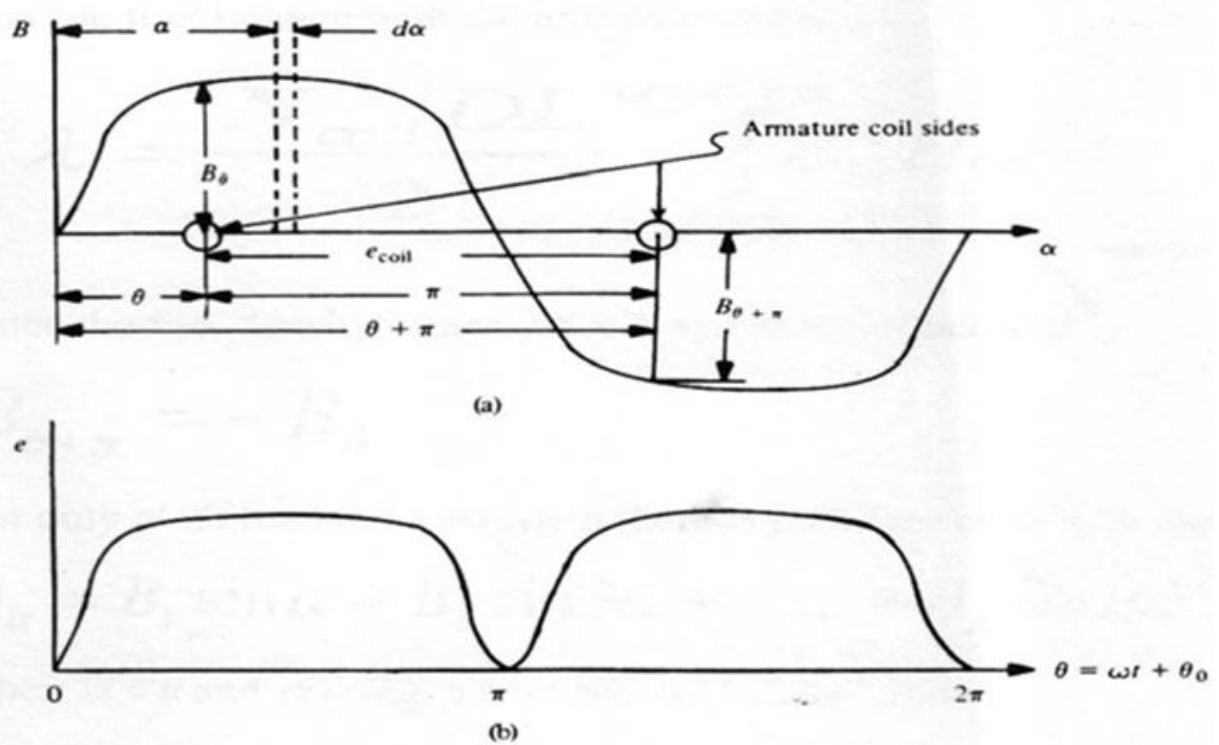

Figure 2 (B):- (a) Flux-density space wave (b) Rectified no-load voltage in a full-pitch coil.

Figure 2(B) shows the approximate flux density distribution curve for a dc machine at no load with the effect of the armature slots neglected. The armature current is zero and the flux is entirely due to the field current. Average voltage induced in the coil of a generator is given by-

$\mathrm{E}_{\text {(coil) }}$ avg $=(2 \mathrm{PN}$ coil $/ \mathrm{d} \mathrm{n}) / 60$

Where $\mathrm{E}_{(\text {(coil) }}$ avg = Average voltage induced in the coil

$\mathrm{P}=$ Number of poles in a machine

$\mathrm{N}_{\text {coil }}=$ Number of coils

$\mathrm{d}=$ Flux per pole

$\mathrm{n}=$ Speed in $\mathrm{rpm}$

\section{Design of wind generator:-}

To generate $200 \mathrm{~W}$, different parameters of wind generator have been calculated. The vertical axis wind rotor diameter is about 2M. Five to seven half circle or NACA -0018(NACA-National Advisory Committee for Aeronautics) profile, curved thin aluminum blades are being fixed vertically at the outmost diameter of the wind rotor. The rotor rotates around the vertical axis shaft which is fitted at 20 to 30 feet height. The rotor shaft is extended to the ground platform where two gears or pulleys are arranged to increase rotor RPM at 600 from $30-40$ RPM. Sixteen poles consisting of 32 permanent magnets size of $\varnothing 28 \mathrm{~mm}$ x $6 \mathrm{~mm}$ are used to generate $100 \mathrm{~W}$ - $200 \mathrm{~W}$ power. For each magnet 100 turns, 15 gauge copper wire is used arround each core material. Main components of wind generator and their measurements are given in the table below-

Table:- Main components of wind generator and their specification.

\begin{tabular}{|l|l|l|l|l|l|}
\hline $\begin{array}{l}\text { Sl. } \\
\text { No. }\end{array}$ & Name of the components & $\begin{array}{l}\text { Diameter } \\
(\mathrm{mm})\end{array}$ & $\begin{array}{l}\text { Thickness/ } \\
\text { Length(mm) }\end{array}$ & Material & $\begin{array}{l}\text { Quantity } \\
\text { (Pieces) }\end{array}$ \\
\hline 1 & Permanent magnet & 28 & 3 & Ferro-magnet & $2 \times 16$ \\
\hline 2 & Disc for permanent magnet & 300 & 10 & Nylon fiber & 2 \\
\hline 3 & Disc for copper coil & 382 & 15 & Nylon fiber & 1 \\
\hline 4 & Flange bush & 108 & 30 & Nylon fiber & 2 \\
\hline 5 & SS shaft & 20 & 350 & SS & 1 \\
\hline 6 & Copper wire for coil & 16 gauge & - & Copper & - \\
\hline 7 & Screw & 6 & 12.7 & $\begin{array}{l}\text { SS } \\
\text { SS }\end{array}$ & $\begin{array}{l}10 \\
4\end{array}$ \\
\hline 8 & & 6 & 254.4 & SS & Body area \\
\hline
\end{tabular}




\section{Construction of wind generator:-}

A wind generator is constructed to extract energy by a vertical axis low speed wind turbine using low speed of the wind. The steps of construction are as bellow-

a. The principle to construct a wind generator is, in an electrical generator, conductor cuts magnetic flux which induced e.m.f. in it.

b. In the present design two discs used for permanent magnet which are rotating and one stationary disc for copper coil or winding.

c. Copper coil disc is placed between two permanent magnets.

d. There is flange bush in the centre of the magnet disc through which the shaft will pass. The diameter of the flange bush is $108 \mathrm{~mm}$ in one side and $32 \mathrm{~mm}$ in another side and thickness is $30 \mathrm{~mm}$. It is attached to magnet disc by screw. Instead of flange bush, one can use $30 \mathrm{~mm}$ thick magnet disc which is costly and make the disc heavy. Another reason to use this flange bush is that, in case of any damage of the disc due to rotation, we need to change the flange bush only. Magnet disc also fixed with shaft by flange bush using screw.

e. There is one coil disc between two magnet discs which contains the winding. Shaft is passed through the center of the disc but they do not touch each other. This disc is attached with cover and makes it stationery.

f. The SS shaft is passed through the center of the discs. Magnet disc rotate on this axis. This shaft is coupled with the wind turbine to rotate the disc and make electricity.

g. Whole arranged component system is surrounded by a cover case made of SS sheet.

\section{The matching procedure:-}

The matching procedure of the wind rotor to the wind generator implies that the following three conditions should be satisfied-

1. Field energy or cut in energy is produced at $\mathrm{V}=\mathrm{V}$ cut-in

2. Tip speed ratio remain close to $\lambda_{0}$ for Vcut-in $<\mathrm{V}<\mathrm{V}$ rated

3. Rotor start turning at

Vstart $<$ V cut-in

For the first case, when required data of the generator and the transmission are known and even for the maximum power co-efficient of the rotor (matching procedure ensures that at $\mathrm{V}=\mathrm{V} \quad$ cut-in the rotor operates at $\mathrm{C}_{\mathrm{pmax}}$ ) this expression gives a value for Vcut-in. If this calculated value turns out to be higher than the value chosen in the calculation, the generator choice was wrong. We need to repeat the procedure. The simplest solution of this problem is to increase the area $\mathrm{A}$ of the rotor, in that case $\mathrm{P}$ rated also increased and it should not exceed maximum power of the generator. If to increase $\mathrm{A}$ is not possible, higher value for $\mathrm{V}$ cut-in has to be accepted, implying number of operating hours per hour.

In practical case for our country,

Wind velocity at which wind generator starts its maximum power output, Vstart $=2.5 \mathrm{~m} / \mathrm{s}$,

Wind velocity at which wind generator starts producing net electricity, $\mathrm{V}$ cut-in $=3.0 \mathrm{~m} / \mathrm{s}$,

Average wind velocity is defined as Vcut-in $/ 0.7$ i.e. $\mathrm{V}$ avg $=3 / 0.7=4.28 \mathrm{~m} / \mathrm{s}$,

Wind speed at which wind generator obtained its maximum power output, $\mathrm{V}_{\text {rated }}=1.5 \times 4.28=6.4 \mathrm{~m} / \mathrm{s}$

To calculate area $\mathrm{A}$ of turbine for power $\mathrm{P}_{\mathrm{a}}=250 \mathrm{~W}$ and $\mathrm{V}=\mathrm{V}_{\text {rated }}=6.4 \mathrm{~m} / \mathrm{s}$ using the equation of power $\mathrm{P}_{\mathrm{a}}=$ $0.1 \mathrm{AV}^{3}$, we get $\mathrm{A}=9.53 \mathrm{~m}^{2}$ and radius of the turbine is $\mathrm{R}=1.75 \mathrm{~m}$.

So to generate $250 \mathrm{~W}$ power the radius of the turbine blade should be $1.75 \mathrm{~m}$. The starting torque of the generator depends on the pressure of the brushes on the commutator (or on the slip rings) and on the value of the field current. It can easily be measured by means of a spring balance and a rope wound the shaft of the generator.

\section{Results and Discussion:-}

Discussion on results obtained from the present research work is described in this section. The total result obtained from this work is aiming to provide electricity to the needy families who live in the remote corners of Bangladesh without any touch of modern development and far away from the reach of national grid. By using this generator, this group of people can turn on light to increase brightness in their daily life.

A. A wind generator for a vertical axis wind turbine of $250 \mathrm{~W}$ generation capacity has been designed.

B. This designed generator has been fabricated with the locally available low cost raw materials. 
C. The wind generator which works at low speed of wind like our country (where average wind speed is $3.5 \mathrm{~m} / \mathrm{s}$ ) is costly and these generators are imported. So this development of wind generator is very much helpful for local operation and production of wind turbines.

D. This generator is suitable for producing electricity in remote areas of Bangladesh and capable to Provide electricity to ful fill the demand of five to six families.

\section{Conclusion:-}

Under this circumstances one can draw the following conclusion regarding the present research work.

a. Life is directly depending on use of electricity and energy crisis is a threat for economical development of Bangladesh. This type of wind turbine and wind generator may be a solution of these power crisis by connecting it to the grid or using it separately in the remote areas where grid connected supply is not possible.

b. Production cost of solar energy is 4 to 5 times greater than the production cost of wind energy. So wind energy is suitable to produce, economically viable for people of low earning group and it is also environment friendly.

c. Unit cost of electricity produced by wind turbine is comparatively low when it is produced at a capacity of over $650 \mathrm{MW}$. As a result, in the remote areas of Bangladesh, multiple number of family can make a group for producing and dissemination of this type of energy.

d. To give a magical touch of modernization to the people of remote areas of Bangladesh, use of renewable energy like wind energy may be a viable option.

e. So Government and private sectors should give emphasis on wind power generation as a effective solution of power crisis in the perspective of Bangladesh.

\section{Referrences:-}

1. Nasima Akter, "Alternative Energy Situation in Bangladesh", URL:http://www.bracresearch.org/reports/alt_energy.pdf

2. Khairul Anam, "Power Crisis \& its Solution through Renewable Energy in Bangladesh", Cyber Journals, Vol. 02, Sep 2011.

3. M.J. Khan, M.T. Iqbal, S. Mahboob, “A wind map of Bangladesh Renewable Energy”, Volume 29, Issue 5, Pages 643-660, April 2004.

4. A. C. Mandal, “Aerodynamics and Design Analysis of Vertical Axis Darrieus Wind Turbines”, Ph.D. Thesis, Vrije Universiteit Bruueesl, Belgium, 1986.

5. M. F. Rahman, "Prospects of Wind Energy in Bangladesh", Proceedings of WorldRenewable Energy Congress (WREC), Denver, Colorado, USA, PP: 806-809, June 15-21, 1996.

6. A. C. Mandal, M. Q. Islam, “ Aerodynamics and Design of Wind Turbines”, Publication Cum Information Office, DAERS, Bangladesh University of Engineering and Technology, Dhaka, Bangladesh, September 2001. 